\title{
Editorial Material: Conceptual Metaphor and Embodied Cognition in Science Learning: Introduction to special issue
}

Tamer G. Amin, Fredrik Jeppsson and Jesper Haglund

\author{
Linköping University Post Print
}

Tweet

N.B.: When citing this work, cite the original article.

This is an electronic version of an article published in:

Tamer G. Amin, Fredrik Jeppsson and Jesper Haglund, Editorial Material: Conceptual Metaphor and Embodied Cognition in Science Learning: Introduction to special issue, 2015, International Journal of Science Education, (37), 5-6, 745-758.

International Journal of Science Education is available online at informaworldTM:

http://dx.doi.org/10.1080/09500693.2015.1025245

Copyright: Taylor \& Francis (Routledge): SSH Titles http://www.routledge.com/

Postprint available at: Linköping University Electronic Press http://urn.kb.se/resolve?urn=urn:nbn:se:liu:diva-118247 


\title{
Special Issue of the International Journal of Science Education: "Conceptual Metaphor and Embodied Cognition in Science Learning"
}

\author{
Guest Editors: \\ Tamer G. Amin, American University of Beirut, Lebanon \\ Fredrik Jeppsson, Linköping University, Sweden \\ Jesper Haglund, Uppsala University, Sweden
}

\section{Table of Contents}

Introduction: Conceptual Metaphor and Embodied Cognition in Science Learning:

Introduction to Special Issue

Tamer G. Amin, American University of Beirut, Lebanon; Fredrik Jeppsson, Linköping University, Sweden; \& Jesper Haglund, Uppsala University, Sweden

Paper 1: The Importance of Language in Students' Reasoning about Heat in Thermodynamic Processes

David Brookes, Florida International University, USA \& Eugenia Etkina, Rutgers University, USA

Paper 2: Varying Use of Conceptual Metaphors across Levels of Expertise in Thermodynamics

Fredrik Jeppsson, Linköping University, Sweden; Jesper Haglund, Uppsala University,

Sweden; \& Tamer G. Amin, American University of Beirut, Lebanon

Commentary: On Conceptual Metaphor and the Flora and Fauna of Mind:

Commentary on Brookes \& Etkina; and Jeppsson, Haglund \& Amin

Bruce Sherin, Northwestern University, USA

Paper 3: Applying Conceptual Blending to Model Coordinated Use of Multiple Ontological Metaphors

Benjamin W. Dreyfus, Ayush Gupta, \& Edward F. Redish, University of Maryland, College Park, USA

Paper 4: Enacting Conceptual Metaphor through Blending: Learning Activities Embodying the Substance Metaphor for Energy

Hunter G. Close, Texas State University, USA \& Rachel E. Scherr, Seattle Pacific University, USA

Commentary: Some Challenges in the Empirical Investigation of Conceptual Mappings and Embodiment in Science Education: Commentary on Dreyfus, Gupta \& Redish; and Close \& Scherr

Rafael Núñez, University of California, San Diego, USA 
Paper 5: An Analysis of Metaphors Used by Students to Describe Energy in an Interdisciplinary General Science Course

Rachel Lancor, Edgewood College, USA

Paper 6: Understanding Starts in the Mesocosm: Conceptual Metaphor as a Framework to Develop External Representations for Science Teaching

Kai Niebert, University of Zurich, Switzerland \& Harald Gropengiesser, Leibniz University Hannover, Germany

Paper 7: From Stories to Scientific Models and Back: Narrative Framing in Modern Macroscopic Physics

Hans U. Fuchs, Zurich University of Applied Sciences at Winterthur, Switzerland

Commentary: Significance of Conceptual Metaphors in Teaching and Learning Science: A Commentary of Lancor; Niebert \& Gropengiesser; and Fuchs

David F. Treagust, Curtin University, Australia \& Reinders Duit, University of Kiel, Germany

Paper 8: Conceptual Metaphor and the Study of Conceptual Change: Research Synthesis and Future Directions

Tamer G. Amin, American University of Beirut, Lebanon 


\section{Conceptual Metaphor and Embodied Cognition in Science Learning: Introduction to Special Issue}

Tamer G. Amin ${ }^{\mathrm{a}}$, Fredrik Jeppsson ${ }^{\mathrm{b}}$ and Jesper Haglund ${ }^{\mathrm{c}}$

a Science and Mathematics Education Center, Department of Education,

American University of Beirut, P.O. Box: 11-0236, Bliss Street, Beirut,

Lebanon, (961)1350-000 ext. 3096, tamer.amin@aub.edu.lb

b Department of Social and Welfare Studies, Linköping University, 60174

Norrköping, Sweden, +46-11-363181, fredrik.jeppsson@liu.se.

c Department of Physics and Astronomy, Uppsala University, Box 516,

75120 Uppsala, Sweden, +46-18-4713544,

jesper.haglund@physics.uu.se.

${ }^{*}$ Corresponding author.

Keywords: Embodied cognition; Conceptual metaphor; Science education 


\section{Orientation and Theoretical Background}

We introduce here a special issue of this journal on the theme of "Conceptual Metaphor and Embodied Cognition in Science Learning." The idea for this issue grew out of a symposium that we organized on this topic at the conference of the European Science Education Research Association (ESERA) in September 2013. The eight papers collected in this issue reflect the emergence of a critical mass of studies in science education applying ideas from the perspective of "embodied cognition" in cognitive science. Up until the 1980s, most research in cognitive science assumed a view of the mind as an abstract information processing system. On this view, our sensorimotor systems were often seen as serving a peripheral, input/output role, conveying information to or from a central cognitive processor where abstract, higher level thought took place. The research focused on developing models of cognition incorporating language-like, propositional representations and syntactic processes, and largely ignored the specifics of human physiology and interaction between the person and the material and social world in which he or she thinks and acts. Since then, several different approaches to cognitive science have adopted some version of the assumption that cognition is embodied - that is, they have assumed that models of cognition need to attend to the characteristics of human brains and bodies, and the material contexts in which thought is taking place (e.g. Barsalou, 2008; Clark \& Chalmers, 1998; Shapiro, 2011; Varela, Thompson, \& Rosch, 1991; Wilson, 2002). The broad assumptions behind embodied cognition are not new to the study of the mind and may be traced back to MerleauPonty's (2002) Phenomenology of perception and Gibson's (1979) ecological theory of perception. They are also acknowledged in cognitive developmental traditions, such as the Piagetian emphasis on our sensorimotor system as a basis for the development of abstract concepts, and resonate with Vygotsky's (1978) recognition of the role of our interaction with physical and symbolic artefacts. With regards to the educational sciences, certain ideas of embodied cognition are in line with pragmatic and progressive traditions, e.g. those of Dewey (1916) which emphasise the role of personal and physical experiences in learning.

Wilson (2002) carefully distinguishes and assesses six distinct claims that fall under the general heading of embodied cognition: (1) that cognitive processes are situated, varying depending on the real-world contexts in which they are carried out; (2) that cognitive processes must be understood with respect to the specific temporal 
constraints imposed on our brains by the environment when cognitive tasks are carried out; (3) that cognitive processes recruit the material, symbolic and social structure of the environment, reducing what actually needs to be performed in the mind itself; (4) that cognitive systems can be viewed as extended, where there is no sharp divide between internal and external contributions to cognition; (5) that the function of cognition is not primarily to represent the external world but to guide action in it; (6) that even cognition that takes place in the "mind" proper relies on knowledge structures that emerge from body-based experiences. This introduction is not the place for a discussion of Wilson's evaluation of these claims. We simply note that she finds the fourth claim "deeply problematic" but cautiously accepts the first three and fifth claims, suggesting that the range of applicability of each still needs to be more fully assessed. The sixth claim she considers to be the most powerful of all the claims and reviews evidence suggesting that body-based cognitive representations and processes ground a wide range of "off-line" mental phenomena such as mental imagery, working memory, episodic memory, implicit memory, and reasoning and problem solving. The research included in this special issue relates to the third and sixth claims reviewed by Wilson. We elaborate on each of these two claims before introducing the eight papers and three commentaries included in the issue.

We begin with the claim (Wilson's Claim Six) that even cognition that takes place in the "mind" proper relies on knowledge structures that emerge from body-based experiences. Research in neuroscience, cognitive psychology and cognitive linguistics has found that mental imagery relies on the same brain mechanisms used for perception and action, that the multicomponent working memory system includes a component that stores visuospatial information to be used to carry out cognitive tasks, and that abstract concepts are understood in terms of generalizations over sensorimotor experiences ("image-schemas") via metaphorical mapping, with reasoning using these abstract concepts also relying on the inferences generated by image schemas (Gibbs, 2005). The latter claim, developed under the label "conceptual metaphor theory" within the field cognitive linguistics has been very influential in the research represented in this special issue.

Conceptual metaphor theory was originally developed by Lakoff and Johnson (1980, 1999). They argued that our conceptual system develops through personal, physical experiences as we interact with the surrounding world. At the most basic level, 
we form image-schemas, knowledge gestalts that emerge out of repeated and pattern sensorimotor experiences when interacting with the surrounding world Johnson, 1987). Examples of image-schemas include the container schema, in which we conceptualise an inside, an outside and a separating boundary; and the source-path-goal schema, through which we conceptualize an object moving along a path, from a source to a goal. Lakoff and Johnson suggested that these image-schemas ground our understanding of abstract concepts and our use of language. One of their central claims is that image-schemas may be mapped metaphorically to more abstract domains forming conceptual metaphors. For instance, by mapping the source-path-goal schema onto the abstract concept of 'love', we may form the conceptual metaphor LOVE IS A JOURNEY, an underlying cognitive structure that finds expression in utterances such as "We're at a crossroads", or "We may have to go our separate ways".

Conceptual metaphor theory was developed initially based on the identification of pervasive and systematic patterns in metaphorical expressions that were found to reflect mappings between conceptual domains of knowledge. Follow-up research in psycholinguistics, neuroscience and gesture analysis has provided further evidence of the psychological reality of the role of image schemas in grounding interpretation of language and reasoning (Gallese \& Lakoff, 2005; Gentner, Bowdle, Wolff, \& Boronat, 2001; Núñez \& Sweetser, 2006). As we describe below, the contributors to this special issue have used the analysis of language and gesture as methods to identify imageschemas invoked by students, teachers and scientists and how they map them metaphorically onto abstract scientific concepts they are thinking about and reasoning with.

The second claim from embodied cognition that features prominently in the research included in this issue (Wilson's Claim Three) is that people recruit the material, symbolic and social structure of their environment, reducing what they actually need to perform in the mind itself. The idea here is that highly complex and abstract cognitive tasks can be guided, simplified or off-loaded onto the structure of physical objects; symbolic representations such as diagrams, mathematical equations and language; and the actual organization of social structures. A prominent example in the embodied cognition literature is Hutchins' (1995) analysis of the complex cognitive task of navigating a large naval vessel. He shows how the cognitive processes taking place within each individual involved in the process is simplified by the actual objects in 
the environment, the instruments and charts used to identify the vessel's location, and the social hierarchy of the officers on the vessel. Another phenomenon that illustrates this claim, in the case of language in particular, has been identified through another strand of research in cognitive linguistics - namely, research on "conceptual integration," or "blending," developed by Fauconnier and Turner (1998). Also accepting embodied cognition assumptions, this line of research has focused on describing the process of meaning construction that takes place as discourse unfolds. From this perspective, constructing meaning involves invocating and integrating conceptual content, triggered by linguistic forms (or elements of other symbol systems). Central to this model is the idea that conceptual content comes from distinct conceptual domains (or "spaces"). Analogical mapping is one well-known example of this process. However, Fauconnier and Turner show that integrating conceptual content while using language can often go beyond mapping from one domain to another. It can often involve blending conceptual content from more than one domain. The outcome of this process is often to greatly simplify the interpretation of complex and abstract meanings and reasoning sequences. Many mundane, and not so mundane, uses of language reveal many subtle and varied mappings once subjected to a conceptual integration analysis.

Let us illustrate how this framework is applied using an example from Turner and Fauconnier (1995). A catamaran sailed from San Francisco to Boston in 1993 in an attempt to break the record established by a clipper in 1853. At some stage after the journey began, a newspaper reported that "the catamaran was "barely maintaining a 4.5 day lead' over the clipper" (cited in Turner \& Fauconnier, 1995). What could 'maintaining a lead' mean here? Turner and Fauconnier suggest that the phrase is understood as referring to a highly simplified fictitious situation where both the catamaran and the clipper are sailing from San Francisco to Boston at the same time. They analyze the interpretation of the phrase in terms of mapping between four conceptual "spaces." They argue that the key to interpreting the phrase is the construction by the listener of a "blended space." They explain that there are two input conceptual spaces (one for each of the 1993 and 1853 sails), a generic space that is structured internally with an abstract schema (e.g., some boat sailing between two cities at some unspecified time), and a blend that is structured by partial input from the two input spaces and the generic space. Both the catamaran and clipper are projected into the blend along with many specifics of the journey of each. However, the specific dates 
are not projected to the blend because including two different times in a single conceptual space would be internally inconsistent. Only a generic time is projected from the generic space to the blend, establishing the idea that the two sails are occurring at the same time. They also point out that what is crucial for the reader to understand the newspaper report is that the fictitious blended space incorporates conceptual relations that are absent in either of the input spaces alone. The presence of two boats simultaneously on the path between the two cities involves relative position between the boats absent in either input. This then encourages a person making sense of the phrase to invoke an imaginary race frame, with a winner and a loser, a sense of competition, etc. Of particular importance for the research included in this special issue is that the blend simplifies the conceptual processes needed to compare the two sails at disparate points in time, compressing it into a race frame that makes it easy to compare the two sails. Fauconnier and Turner (2002) have discussed how such blends are pervasive in language as well as in the construction and interpretation of other symbol systems like gestures, diagrams and objects with symbolic meaning (e.g. a watch face). As will be explained below, research in science education has begun to explore how language, gesture and objects (including the human body) can be shown to support the simplification of scientific conceptualization and reasoning in abstract domains.

The science education research included in this special issue applies these two assumptions from embodied cognition - the grounding of mental processes in bodybased knowledge structures and the offloading and simplification of cognitive processes onto external objects and symbols (including both language and gesture). This research uses theoretical constructs and methods from the two strands of research in cognitive linguistics introduced above: conceptual metaphor theory (Lakoff \& Johnson, 1980, 1999) and conceptual integration or blending theory (Fauconnier \& Turner, 1998). This research in science education is not unique in the educational literature. Glenberg (2008) and Kontra, Goldin-Meadow and Beilock (2012) have recognised the role of embodied cognition in education and concept learning. In particular, a special issue was recently dedicated to embodied approaches to mathematics education in the Journal of the Learning Sciences (Hall \& Nemirovsky, 2012). The perspectives of conceptual metaphor and conceptual integration have been used to analyse language use and conceptualisation in technical, as well as everyday thought and language. Lakoff and Núñez (2000) show that conceptual metaphors are heavily involved in how we 
structure one of the most formal and abstract areas of human thought - mathematics. For instance, the idea of an equation builds on a balance schema, involving experiences such as equal weights on a scale. Similarly, building on conceptual metaphors, Sfard (1994) shows how we treat abstract entities, such as numbers and functions, as objects through a process of reification. The special issue on embodied learning in mathematics, referred to above, involves themes such as how we make use of the container, proximity and source-path-goal schemata in learning to read analogue clocks (Williams, 2012), how learning of complex numbers is enhanced by body motion on a tiled floor (Nemirovsky, Rasmussen, Sweeney, \& Wawro, 2012), and how gestures can be used to reveal image-schematic underpinnings of mathematical cognition (Alibali \& Nathan, 2012).

Within science education, the ideas of Lakoff and Johnson (1980) were possibly first recognised by Andersson (1986) who suggested that learners make sense of a range of phenomena, including phase transitions, mechanics and electric circuits, by use of an experiential gestalt of causation, a schema of how an agent affects an object in interaction. Within physics education research, Podolefsky and Finkelstein (2007) have analysed how increasingly abstract phenomena have been interpreted in terms of waves (from water waves, through sound and electromagnetism, to quantum phenomena) from the perspective of blending theory. Wittmann (2010) has used blending theory to explain that it is tempting, although misleadingly, for students to use their experience of throwing balls when identifying factors that impact the speed of propagation of a wave on a suspended string. Questions of embodiment and the use of theories from cognitive linguistics have only recently received sustained and systematic attention in science education. The eight contributions to this special issue represent a number of research programs central to this body of work. All contributions draw on assumptions from the perspective of embodied cognition to examine issues in scientific cognition, science learning and instruction. Collectively, the contributions address concepts that span the areas of physics, chemistry, biology, and climatology. As we point out below, the papers engage with issues central to research in science education such as the difference between novice and expert thinking, including differences in how concepts are categorized ontologically; the nature and source of student conceptions; the role of metaphor and analogy in concept learning; and the role of representations and narrative in science instruction. 


\section{Contributions to this Special Issue}

The issue includes eight papers and three commentaries. The papers are grouped thematically with each of three sets of papers followed by a commentary. The first two papers (by Brookes and Etkina; and Jeppsson, Haglund and Amin) address the issue of how the phenomenon of conceptual metaphor figures in the acquisition of scientific expertise. In a commentary, Bruce Sherin discusses the basic theoretical assumptions guiding these two studies and how they can be situated in relation to other work in science education. The next set of two papers (by Dreyfus, Gupta and Redish; and Close and Scherr) both use the perspective of conceptual integration (or blending). These papers explore how learners and scientists blend multiple metaphors and how thinking with conceptual metaphors interacts with the use of external representations. These papers use analyses of language and gesture to argue that such blends and interactions are productive in learning and suggest approaches to instruction of difficult concepts. In his commentary on this second set, Rafael Núñez engages in careful analysis of the methods used in these two studies, focusing in particular on the analysis of gestures. A third set of three papers (by Lancor; Niebert and Gropengießer; and Fuchs) address the contribution of a conceptual metaphor perspective to identifying the narrative structure inherent in science, analyzing student and scientist conceptions, and designing instructional representations. In a joint commentary, David Treagust and Reinders Duit reflect on these three papers and examining the extent to which this work goes beyond prior research on narrative, metaphor, analogy and multiple representations in science education. The eighth paper in the issue (by Amin) reviews the literature on conceptual metaphor in science education to identify its contributions to the study of conceptual change and suggests directions for future research. In the remainder of this section, we introduce each of these contributions, situating them very briefly in relation to the authors' programs of research.

Brookes and Etkina $(2007,2009)$ began a program of research in the last few years, drawing on the theory of conceptual metaphor to analyze the language of science (in the domains of force and motion, and quantum mechanics), to describe the ontological classification of concepts (Chi \& Slotta, 1993) implicit in this language, and to reveal conceptual misunderstandings made by students that can be traced to these implicit ontologies. Their contribution in this special issue continues this line of work. 
However, in their paper here, they address the connections between language and students' conceptual difficulties more directly and make a clear distinction between explicit ontological beliefs about a concept (in this case heat) and conceptualizations implicit in language but revealed through conceptual metaphor analysis. Their study provides evidence linking non-canonical explicit ontological beliefs about the meaning of the word 'heat' and conceptualizations of heat as a substance implicit in students' language, on the one hand, to incorrect reasoning with the concept of heat as if it is a state function when solving thermodynamics problems, on the other. While providing empirical evidence for this link between language and state-function reasoning about heat, Brookes and Etkina are cautious not to impose a simple causal interpretation. Instead, they assume a bidirectional causal relationship between the conceptualizing of experience and language. From this perspective on language and conceptualization in science and based on their empirical results, they articulate an approach to science instruction as guided meaning making (following Lemke, 1998). In this approach, students are encouraged to avoid using technical terminology early on as they make sense of observations and construct explanations of phenomena. As a technical term is introduced, students are expected make sure that its use and the meaning attributed to it are shared in the classroom. Brookes and Etkina believe that they can, thereby, avoid both extremes of allowing students to unproductively use language with misleading implicit ontologies and avoid the forced emphasis on using ontologically "precise" language advocated by some science educators.

In the next contribution to this issue, Jeppsson, Haglund and Amin hypothesize that implicit metaphorical construals of concepts such as heat and entropy (which are "incorrect" from a scientific perspective) can contribute productively to expert scientific reasoning. In previous work together with Strömdahl, they have shown the pervasive and systematic use of such metaphorical construals of the concept of entropy and the second law of thermodynamics in university level textbooks (Amin, Jeppsson, Haglund, \& Strömdahl, 2012) and scientific problem-solving carried out by $\mathrm{PhD}$ students (Jeppsson, Haglund, Amin, \& Strömdahl, 2013). That work showed that substance-like construals of abstract concepts seem to be productively used by experts in problem solving and in communicating ideas to learners. The work reported by Jeppsson et al. here, contrasts the use of conceptual metaphors in problem solving at two levels of expertise: PhD students and undergraduates. A pair of undergraduate students were 
given the same thermodynamics problems involving the concept of entropy that were given to the pair of PhD students in Jeppsson et al. (2013). Qualitative analysis of the problem solving protocol for each of the pair of students revealed differences in how the two pairs used conceptual metaphors. The authors distinguish their approach to others in the expertise literature who focus either on the role of propositional representations (e.g. Chi, Feltovich, \& Glaser, 1981) or on the role of non-propositional representations or processes (such as imagery, mental models or analogical reasoning) (e.g. Clement, 2009). In contrast, Jeppsson et al. interpret the patterns of use of the conceptual metaphors at different levels of expertise in terms of the nature of the coordination between propositional and non-propositional knowledge resources and processes. A key hypothesis from the analysis was that the more expert problem solvers (the $\mathrm{PhD}$ students) used conceptual metaphors more extensively and in a less conventional way than the undergraduates, while constraining their use of these metaphors in light of propositional laws and principles that were invoked initially to launch the problem solving. Jeppsson et al. argue that the strategic use of conceptual metaphor in coordination with propositional principles is a feature of problem solving that needs to be acquired with expertise. Given the highly implicit nature of this aspect of problem solving, they argue that exposure to how experts coordinate these resources in apprenticeship settings must be an important component of instructional environments.

Bruce Sherin has contributed a commentary on the first two papers in this issue. He engages in a broad discussion of the theoretical frameworks adopted in these two papers and how they position themselves with respect to other lines of work in science education. He comments that he views the major contributions of these papers to be their attention to the more advanced levels of scientific expertise, to how a variety of different resources are weaved together in advanced scientific thought, and the attention given to language a tool for thought, not just as a window onto thought of value to the researcher. Sherin, however, takes issue with how Jeppsson, Haglund and Amin position their research with respect to other related work in science education. In addition, he argues that the construct of conceptual metaphor is used without attention to nuances among different kinds of mental structures. He also rejects what he sees as an exclusive assumption that concepts can only derive meaning by grounding in the body and insists that a notion of mental representation of concepts independent of 
external representations like language is needed. In sum, he argues for a more inclusive approach to the "flora and fauna of the mind" when researching science learning and instruction.

The next two articles (by Dreyfus, Gupta and Redish; and Close and Scherr) use the blending framework to study scientists', teachers' and students' understanding and representation of the concept of energy, by analyzing language, gesture and other embodied activities. In the first of this pair, Dreyfus et al. build on their research on context-dependence and flexibility of ontological categorisation in science and science learning (Gupta, Hammer, \& Redish, 2010) and ontological metaphors for negative energy (Dreyfus et al., 2014). They examine how a physics professor and one of his students make use of a blend of two metaphors for energy when conceptualizing chemical bonds: energy-as-substance and energy-as-location. In the episodes they analyse, they find that the metaphor energy-as-substance is expressed in language, while energy-as-location is expressed simultaneously by means of gestures and the vertical dimension of a graph representing energy levels on the whiteboard. They argue that the two are integrated, forming a coherent blend. The blend is introduced by the professor in a lecture and later adopted by the student in a subsequent interview on the energy transfer involved in ATP synthesis. Dreyfus et al. argue that this finding is not consistent with the view that students' and scientists' conceptions can be classified into distinct ontological categories (Chi, Slotta, \& De Leeuw, 1994). In contrast, they show that physicists and students may embrace, simultaneously, at least two such categories. This research shows how the substance metaphor of energy can be complemented with other construals of energy to give a more comprehensive idea of the concept in physics teaching.

The second paper in this pair reports on part of a project that looks to redesign undergraduate science teaching and conduct innovative professional development for teachers at Seattle Pacific University. In this Energy Project, Scherr and colleagues have developed representations and a learning environment that help learners adopt embodied construals of physical processes involving energy transfers and transformations. In their previous work, they explicitly exploited a substance metaphor for energy (Scherr, Close, McKagan, \& Vokos, 2012). An example is the Energy Theater, a kind of structured, embodied role play, in which participants represent one unit of energy each with their bodies and depict the objects that contain the unit of energy 
through their location on a floor delimited with loops of rope and the form of energy with gestures (Scherr et al., 2013). In their contribution here, Close and Scherr analyse participants' Energy Theater enaction of a physical scenario, adiabatic compression of a gas, using blending theory. The physical scenario to be represented and the setting of the Energy Theater, with its ropes and the participants themselves, constitute the two input spaces for the blend. Certain characteristics of energy are anchored materially and socially (Hutchins, 1995) through the rules of Energy Theater. For instance, energy conservation is guaranteed as part of the game, since the participants themselves corresponding to units of energy - cannot suddenly appear or disappear. The participants can therefore focus their attention on understanding the specific nature of physical scenarios they are confronted with. Close and Scherr analyze participants' discussions and bodily enactments using blending theory to show how the participants make conceptual leaps in their understanding of energy during an Energy Theater performance.

Rafael Núñez has contributed a commentary on these two closely related papers. Núñez is immersed in the foundational cognitive science literature on conceptual metaphor and blending, having contributed to its theoretical development (in particular in the domain of mathematical cognition) and to the development of methods, including the analysis of gesture. He brings this background to his discussion of these two papers. He is excited by the extension of these contemporary theories and methods in cognitive science to the context of science education, with the rich possibilities it brings to investigating the complexity of multimodal meaning making in science classrooms. He comments, however, that this complexity brings methodological challenges. He discusses two in particular, illustrating these through a close critical reading of the analyses presented by Dreyfus et al. and Close and Scherr. The first problem he points out is with the characterization of the source domains of the conceptual metaphors identified. The second is the diversity of kinds of gestures and the challenge this diversity raises for inferring when particular gestures do or do not provide evidence for blending. He concludes by challenging science education researchers drawing on embodied cognition theories and methods to fine tune their methods so as to add greater rigor to empirical investigations in what is a complex and challenging area of investigation. 
In the next three papers (by Lancor; Niebert and Gropengießer; and Fuchs, the perspective of conceptual metaphor is used to characterize student conceptions across a number of scientific topics, to design instructional representations, and to identify the inherent narrative structure of a scientific domain and make a curricular recommendation to use narrative to prepare children for science in the early years. In the first of these papers, Lancor extends her earlier work investigating the range of analogies and metaphors for energy used in teaching and by students across a range of introductory college courses including biology, chemistry, and physics. In this work, she has used the theory of conceptual metaphor and has identified six conceptual metaphors for energy. All of these are versions of the metaphorical construal of energy as a substance, but each highlights and obscures subtly different aspects of the concept (Lancor, 2014a). Lancor (2014b) has used this framework to analyse analogies for energy generated by students in physics, chemistry and biology courses. In her contribution to this special issue, she investigates how undergraduate students taking an interdisciplinary general science course make use of metaphor for energy when explaining the role of energy in relation to radiation, transportation, generating electricity, earthquakes, and the big bang theory. When comparing the results from Lancor (2014a), she finds that the same framework of conceptual metaphors can used in this interdisciplinary context as well. She reports the patterns of use of the six metaphors by students across topics and compares these patterns to findings from the disciplinary contexts. In light of the results of her study, Lancor argues that the framework of six conceptual metaphors for energy that she has developed offers a potential analytical lens which can be used as a way to reveal students' conceptual understanding, suggesting that it can be used by teachers as a formative assessment tool.

Also using Lakoff and Johnson's conceptual metaphor framework, Harald Gropengießer and colleagues at the University of Hannover have developed a range of learning activities building on the idea of experientialism (Gropengießer, 2007; Riemeier \& Gropengießer, 2008). Drawing on the prior work of Gropengießer and colleagues, Niebert, Marsch, and Treagust (2012) analysed a wide range of instructional analogies and metaphors used in science texts and science education research studies, and argued that those that are particularly effective are those that make use of students' embodied personal experiences as source domains. In their contribution to this special issue, 
Niebert and Gropengießer present an analysis of student interviews on conceptions of the greenhouse effect, carbon cycle, cell division and neurobiology. Using a conceptual metaphor perspective, they identify students' understanding in these domains which span macrocosmic (e.g. as in climate change) and microscopic (e.g. as in cell division) scales. By identifying image-schemas that students apply that lead them to misconceptions in these domains, the authors uncover the "learning demand" in each case. They then use this information to design effective instructional representations and evaluate their effect on student understanding through teaching experiments. Niebert and Gropengießer argue that understanding difficult concepts in science and, by implication, the design of instructional representations need to rely on knowledge acquired at the mesocosmic level.

Based on several years of teaching experiences in the field of thermodynamics and drawing on the literature on embodied cognition, Hans Fuchs has developed a novel approach to thermodynamics instruction (Fuchs, 1987, 2010). He has argued that image schemata (Johnson, 1987), especially force-dynamic gestalts, are used in making sense of thermodynamic processes (Fuchs, 2007). In his theoretical contribution here, Fuchs describes how image-schemas are used to frame everyday situations and thermodynamic processes as narratives (Bruner, 1996). Fuchs analyses a story for children about cold gripping a village during winter, Sadi Carnot's account of heating water in a kettle, and modern continuum thermodynamics. He uncovers the imageschemas that structure understanding of heat in these different contexts and shows how they combine to frame these diverse situations as narratives. He concludes by arguing that this suggests a role for a particular use of stories in early science instruction that can prepare children for the scientific thinking they will be expected to develop at more advanced stages.

In their commentary, David Treagust and Reinders Duit reflect on the papers by Lancor, Niebert and Gropengießer, and Fuchs. Treagust and Duit present their comments on these papers in relation to their prior, highly influential work on metaphors, analogies and multiple representations in conceptual change. In their commentary, they distinguish the three papers in terms of the extent to which they depart from what they refer to as "classical" views on conceptual change, to which they have both contributed. They comment that the paper by Lancor seems to fit most clearly within the classical tradition, given the absence of an explicit reference to embodiment 
in her use of the conceptual metaphor framework. In their view, the novelty of Lancor's research is in extending accounts of student conceptions of energy beyond physics to other domains like chemistry and biology as well as interdisciplinary contexts. In their comment on Niebert and Gropengießer's paper, they find praiseworthy the theoretical synthesis of an embodied cognition perspective with prior work on multiple representations in science. They find particularly interesting the connections made to evolutionary epistemology, through the idea that human perceptual systems were designed to represent the world at the intermediate scale of the mescosm. They see great promise in this perspective as it is able to lead to successful instructional interventions in challenging domains of science. In Fuchs' theoretical proposal, they see a perspective on narrative in science and science learning that goes beyond prior work on narrative in science education and provides insights into the roles of models in science, science teaching and learning. They comment, however, that the argument used for developing this perspective of "narrative framing" is complex and would need to be presented in a simpler and clearer language if it is to be communicated effectively to teachers. Overall, Treagust and Duit view this collection of papers as providing a lot of information about "conceptual metaphor in action" with all papers showing how a conceptual metaphor perspective can make a contribution to effective instruction in science. They suggest, however, that greater precision and consistency is needed in the use of the construct of conceptual metaphor across authors.

The final paper in this issue (by Amin) is a review of the literature on conceptual metaphor in science education. Amin (2009) had made a case for the relevance of a conceptual metaphor perspective for understanding conceptual change. However, the last seven or eight years has seen the emergence of research programs investigating different aspects of conceptual metaphor in science education as is reflected in this special issue. In his contribution to this issue, Amin reviews this literature with the specific goal of clarifying its contributions to the study of conceptual change. This paper first draws on Amin, Smith and Wiser (2014) to present a highly condensed historical overview of research on conceptual change. The literature on conceptual metaphor is then reviewed so as to clarify its contributions to characterizing student and scientific misconceptions, identifying obstacles to learning, characterizing the process of conceptual change and designing effective instruction. However, Amin points out differences among researchers on conceptual metaphor in science education and 
suggests that this perspective has still not provided an explicit account of concepts. He briefly presents a way of viewing concepts while incorporating attention to the phenomenon of conceptual metaphor. He suggests directions for future research using a conceptual metaphor that could contribute further to the study of conceptual change.

We hope that by bringing together these papers and commentaries on conceptual metaphor and embodied cognition in science learning in this issue, we will encourage further exploration, discussion and debate regarding the issues raised in its pages.

\section{Acknowledgements}

This special issue grew out of a symposium on Conceptual Metaphor and Embodied Cognition in Science Learning at the European Science Education Research Association (ESERA) in September 2013. David Treagust graciously agreed to serve as discussant in this symposium. It was his formal discussant's reflections on the papers included in the symposium and our informal discussions with him afterwards that led to this project. We are grateful to David for encouraging us to put together this special issue.

\section{References}

Alibali, M. W., \& Nathan, M. J. (2012). Embodiment in mathematics teaching and learning: Evidence from learners' and teachers' gestures. Journal of the Learning Sciences, 21(2), 247-286.

Amin, T. G., Jeppsson, F., Haglund, J., \& Strömdahl, H. (2012). The arrow of time: metaphorical construals of entropy and the second law of thermodynamics. Science Education, 96(5), 818-848.

Andersson, B. (1986). The experiential gestalt of causation: a common core to pupils' preconceptions in science. European Journal of Science Education, 8(2), 155-171.

Barsalou, L. (2008). Grounded cognition. Annual Review of Psychology, 59(1), 617-645.

Brookes, D. T., \& Etkina, E. (2007). Using conceptual metaphor and functional grammar to explore how language used in physics affects student learning. Physical Review Special Topics - Physics Education Research, 3(1), 010105.

Brookes, D. T., \& Etkina, E. (2009). "Force," ontology, and language. Physical Review Special Topics - Physics Education Research, 5(1), 010110. 
Chi, M. T. H., Feltovich, P. J., \& Glaser, R. (1981). Categorization and representation of physics problems by experts and novices. Cognitive Science, 5(2), 121-152.

Chi, M. T. H., \& Slotta, J. D. (1993). The ontological coherence of intuitive physics. Cognition and Instruction, 10(2-3), 249-260.

Chi, M. T. H., Slotta, J. D., \& De Leeuw, N. (1994). From things to processes: A theory of conceptual change for learning science concepts. Learning and Instruction, 4(1), 27-43.

Clark, A., \& Chalmers, D. (1998). The extended mind. Analysis, 58(1), 7-19.

Clement, J. (2009). Creative model construction in scientists and students: the role of imagery, analogy, and mental simulation. Dordrecht, NL: Springer.

Dewey, J. (1916). Democracy and education: An introduction to the philosophy of education. New York, NY: McMillan.

Dreyfus, B. W., Geller, B. D., Gouvea, J., Sawtelle, V., Turpen, C., \& Redish, E. (2014). Ontological metaphors for negative energy in an interdisciplinary context. Physical Review Special Topics - Physics Education Research, 10(2), 020108.

Fauconnier, G., \& Turner, M. (1998). Conceptual integration networks. Cognitive Science, 22(2), 133-187.

Fauconnier, G., \& Turner, M. (2002). The way we think: conceptual blending and the mind's hidden complexities. New York, NY: Basic Books.

Fuchs, H. U. (1987). Entropy in the teaching of introductory thermodynamics. American Journal of Physics, 55(3), 215-219.

Fuchs, H. U. (2007). From image schemas to dynamical models in fluids, electricity, heat and motion. An essay on physics education research. Retrieved 26 October, 2012, from https://home.zhaw.ch/ fusa/COURSES/IO/Files V/PER Essay.pdf.

Fuchs, H. U. (2010). The dynamics of heat: A unified approach to thermodynamics and heat transfer (2nd ed.). New York, NY: Springer.

Gallese, V., \& Lakoff, G. (2005). The brain's concepts: the role of the sensory-motor system in conceptual knowledge. Cognitive Neuropsychology, 22(3-4), 455-479.

Gentner, D., Bowdle, B. F., Wolff, P., \& Boronat, C. (2001). Metaphor is like analogy. In D. Gentner, K. J. Holyoak, \& B. K. Kokinov (Eds.), The analogical mind: Perspectives from cognitive science (pp. 199-254). Cambridge, MA: MIT Press.

Gibbs, R. W. (2005). Embodiment and cognitive science. Cambridge, UK: Cambridge University Press. 
Gibson, J. J. (1979). The ecological approach to visual perception. Boston, MA: Houghton Mifflin.

Glenberg, A. M. (2008). Embodiment for education. In P. Calvo \& T. Gomila (Eds.), Handbook of cognitive science: an embodied approach (pp. 355-372). Oxford, UK: Elsevier Science.

Gropengießer, H. (2007). Theorie des erfahrungsbasierten Verstehens [The theory of experientialism]. In D. Krüger \& H. Vogt (Eds.), Theorien in der Biologiedidaktischen Forschung (pp. 105-116). Berlin, Germany: Springer.

Gupta, A., Hammer, D., \& Redish, E. F. (2010). The case for dynamic models of learners' ontologies in physics. Journal of the Learning Sciences, 19(3), 285-321.

Hall, R., \& Nemirovsky, R. (2012). Introduction to the special issue: Modalities of body engagement in mathematical activity and learning. Journal of the Learning Sciences, 21(2), 207-215.

Hutchins, E. (1995). Cognition in the wild. Cambridge, MA: MIT Press.

Jeppsson, F., Haglund, J., Amin, T. G., \& Strömdahl, H. (2013). Exploring the use of conceptual metaphors in solving problems on entropy. Journal of the Learning Sciences, 22(1), 70-120.

Johnson, M. (1987). The body in the mind: the bodily basis of meaning, imagination, and reason. Chicago, IL: University of Chicago Press.

Kontra, C., Goldin-Meadow, S., \& Beilock, S. L. (2012). Embodied learning across the life span. Topics in Cognitive Science, 4(4), 731-739.

Lakoff, G., \& Johnson, M. (1980). Metaphors we live by. Chicago, IL: The University of Chicago Press.

Lakoff, G., \& Johnson, M. (1999). Philosophy in the flesh. New York, NY: Basic Books.

Lakoff, G., \& Núñez, R. E. (2000). Where mathematics comes from: How the embodied mind brings mathematics into being. New York, NY: Basic Books.

Lancor, R. A. (2014a). Using metaphor theory to examine conceptions of energy in biology, chemistry, and physics. Science \& Education, 23(6), 1245-1267.

Lancor, R. A. (2014b). Using student-generated analogies to investigate conceptions of energy: A multidisciplinary study. International Journal of Science Education, $36(1), 1-23$. 
Lemke, J. L. (1998). Teaching all the languages of science: words, symbols, images and actions. Retrieved 10 January, 2011, from http://academic.brooklyn.cuny.edu/education/ilemke/papers/barcelon.htm.

Merleau-Ponty, M. (2002). Phenomenology of perception (C. Smith, Trans.). London, UK: Routledge.

Nemirovsky, R., Rasmussen, C., Sweeney, G., \& Wawro, M. (2012). When the classroom floor becomes the complex plane: Addition and multiplication as ways of bodily navigation. Journal of the Learning Sciences, 21(2), 287-323.

Niebert, K., Marsch, S., \& Treagust, D. F. (2012). Understanding needs embodiment: A theory-guided reanalysis of the role of metaphors and analogies in understanding science. Science Education, 96(5), 849-877.

Núñez, R. E., \& Sweetser, E. (2006). With the future behind them: Convergent evidence from Aymara language and gesture in the crosslinguistic comparison of spatial construals of time. Cognitive Science, 30(3), 401-450.

Podolefsky, N. S., \& Finkelstein, N. D. (2007). Analogical scaffolding and the learning of abstract ideas in physics: An example from electromagnetic waves. Physical Review Special Topics - Physics Education Research, 3(1), 010109.

Riemeier, T., \& Gropengießer, H. (2008). On the roots of difficulties in learning about cell division: Process-based analysis of students' conceptual development in teaching experiments. International Journal of Science Education, 30(7), 923-939.

Scherr, R. E., Close, H. G., Close, E. W., Flood, V. J., McKagan, S. B., Robertson, A. D., . . Vokos, S. (2013). Negotiating energy dynamics through embodied action in a materially structured environment. Physical Review Special Topics - Physics Education Research, 9(2), 020105.

Scherr, R. E., Close, H. G., McKagan, S. B., \& Vokos, S. (2012). Representing energy. I. Representing a substance ontology for energy. Physical Review Special Topics Physics Education Research, 8(2), 020114.

Sfard, A. (1994). Reification as the birth of metaphor. For the Learning of Mathematics, 14(1), 44-55.

Shapiro, L. A. (2011). Embodied cognition. New York, NY: Routledge.

Turner, M., \& Fauconnier, G. (1995). Conceptual integration and formal expression. Metaphor and Symbolic Activity, 10(3), 183-204. 
Varela, F. J., Thompson, E., \& Rosch, E. (1991). The embodied mind: cognitive science and human experience. Cambridge, MA: MIT Press.

Williams, R. F. (2012). Image schemas in clock-reading: Latent errors and emerging expertise. Journal of the Learning Sciences, 21(2), 216-246.

Wilson, M. (2002). Six views of embodied cognition. Psychonomic Bulletin \& Review, $9(4), 625-636$.

Wittmann, M. C. (2010). Using conceptual blending to describe emergent meaning in wave propagation. Paper presented at the 9th International Conference of the Learning Sciences, ICLS '10, Chicago, IL. http://arxiv.org/abs/1008.0216

Vygotsky, L. S. (1978). Mind in society: The development of higher psychological processes. Cambridge, MA: Harvard University Press. 